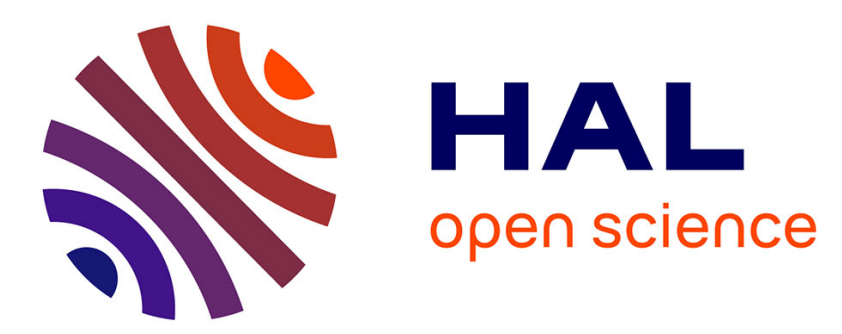

\title{
Strategies in intervention programmes for obese youth: implication of the age and the type of physical activities
}

Jeremy Vanhelst, Paul S Fardy, Laurent Beghin, Gilles Bui-Xuan, Jacques

Mikulovic

\section{- To cite this version:}

Jeremy Vanhelst, Paul S Fardy, Laurent Beghin, Gilles Bui-Xuan, Jacques Mikulovic. Strategies in intervention programmes for obese youth: implication of the age and the type of physical activities. Clinical Physiology and Functional Imaging, 2015, 35 (1), pp.17-20. 10.1111/cpf.12112 . hal-02177639

\section{HAL Id: hal-02177639 \\ https://hal.univ-lille.fr/hal-02177639}

Submitted on 9 Jul 2019

HAL is a multi-disciplinary open access archive for the deposit and dissemination of scientific research documents, whether they are published or not. The documents may come from teaching and research institutions in France or abroad, or from public or private research centers.
L'archive ouverte pluridisciplinaire HAL, est destinée au dépôt et à la diffusion de documents scientifiques de niveau recherche, publiés ou non, émanant des établissements d'enseignement et de recherche français ou étrangers, des laboratoires publics ou privés. 
Strategies in intervention programs for obese youth: implication of the age and the type of physical activities

Jérémy Vanhelst ${ }^{1-2}$, Laurent Béghin ${ }^{1-2}$, Paul Stephen Fardy ${ }^{3}$, Gilles Bui-Xuan ${ }^{4}$, Jacques Mikulovic ${ }^{5}$

${ }^{1}$ Centre d'Investigation Clinique, CIC-9301-Inserm-CH\&U, Lille, France

${ }^{2}$ Unité Inserm U995 \& Université Lille Nord de France, Lille, France

${ }^{3}$ Department of Family, Nutrition, and Exercise Sciences (FNES), Queens College, Flushing, NY, USA

${ }^{4}$ ER3S, Université d'Artois, 59658 Villeneuve d'Ascq, France

${ }^{5}$ ER3S, EA 4110, ULCO, 59240 Dunkerque, France

Corresponding author: J. Vanhelst

Centre d'Investigation Clinique, CIC-9301-Inserm-CH\&U, CHRU de Lille 59037 Lille Cedex Tel: 0320446126

Fax: 0320446134

Email: jeremy.vanhelst@chru-lille.fr

Short title: Intervention program in obese youth 


\begin{abstract}
The aim of this study was to assess the effects of age and type of physical activity on anthropometric measures of obese youth participating in an intervention program. Subjects included 37 obese children $(12.5 \pm 2.9 \mathrm{yrs})$. The program consisted of a unique program of physical activity and health education. Assessments included body mass index, body composition, and ability to perform sport activities. Paired t tests were used to assess the effects of intervention and chi square was used to assess inter-action between measures. Findings suggest significant decrease in $\mathrm{Z}$ scores of Body Mass Index and an improvement of the ability to perform sport activities $(\mathrm{p}<0.05)$. The effectiveness of the program has more impact on children than adolescents $(\mathrm{p}<0.05)$. Improvements were greater in team vs. net sports $(\mathrm{p}<0.05)$. Results show that intervention strategies have to be different according to the age in order to have a favourable effect on anthropometric characteristic and the consequences of obesity childhood and adulthood. The findings suggest that the intervention program was of greater benefit for children than adolescents.
\end{abstract}

Keywords: Rehabilitation, Pediatrics, Obesity, Physical activity, Strategies 


\section{Introduction}

Pediatric obesity is alarming and epidemic problem in Western industrialized countries. Obesity in youth is associated with adverse health consequences in adults such as coronary heart disease, diabetes, and some cancers. Studies show that high normal weight in childhood predicts overweight or obesity as an adult and elevated Body Mass Index (BMI) in childhood predicted risk of hypertension in young adulthood (Dietz, 1998; Whitaker, Wright, Pepe, Seidel, \& Dietz, 1997; Filed, Cook, \& Gillman, 2005). Other consequences of obesity include sleep apnea, orthopaedic complications, asthma, poor quality of life and hypertension (Wabitsch, Hauner, Heinze, Muche, Bockmann, \& Parthon, 1994; Chin \& Rona, 2001; Von Mutius, Schwartz, Neas, Dockery, \& Weiss, 2001; Mcmurray, Harrell, Bangdiwala, Bradley, Denug, \& Levine, 2002; Dahlberg, Bergkvist, Hekmat, \& Svensson, 2008; Jasik \& Lustig, 2008; Gozal \& Kheirandish-Gosal, 2009).

Clinical interventions with differing methodologies have been developed to treat obesity. Physical activity training is regarded as an effective approach recognized for longterm weight maintenance (Van Dale, Saris, \& Ten Hoor, 1990). Another successful strategy is restricting diet caloric intake (Epstein, Paluch, Beecher, \& Roemmich, 2008).

Physical activity is widely recognized for its positive impact on health and important role in the prevention and treatment of chronic diseases such as obesity (Ekelund, Griffin, \& Wareham, 2007; Pedersen \& Saltin, 2006). Physical activity is represented by three components, the duration, the frequency and the intensity. Studies have shown that intensity, frequency and duration of activity are important factors in having a positive impact on childhood obesity (Atlantis, Barnes, \& Singh, 2006; Horowitz \& Klein, 2000; Achten, Gleeson, \& Jeukendrup, 2002; Lazzer, Busti, Agosti, De Col, Pozzo, \& Sartorio, 2007). However, to the best of our knowledge, there is no study assessing the effectiveness of the 
type of physical activity on obese youth. Such information would provide valuable information for successful program development.

The objective of this study was to assess the influence of age and type of physical activity on anthropometric measures of obese youth.

\section{Participants and Methods}

The current report is based on data derived from an intervention program on obese youth (Vanhelst, Marchand, Fardy, Zunquin, Loeuille, Renaut, et al., 2010). The aim of the program was to improve the health of obese youth by reducing obesity and improving cardiovascular health, physical fitness, sleep, and self-esteem. Data were collected during 2008 and 2010 in Northern France. In total, 37 obese youth ages $12.5 \pm 2.9$ yrs (18 girls and 19 boys) participated in the study. A detailed description of the program has been published elsewhere (Vanhelst, et al., 2010). In summary, physical training consisted of many moderate to vigorous activities, including team and net sports, such as basketball, football, tennis, badminton, and handball. Physical activity consisted of 2-hour sessions once each week in a gymnasium for one year using the Conative Educational Model (Mikulovic, Bui-Xuan, \& Marcellini, 2002; Bui-Xûan, 1999). The conative educational approach is based on the idea of conative curriculum which models a sense given by to one's actions (Bui-Xûan, 1999). Identifies five impetus which lead one's actions. This model allows the resarcher to identify conative stages through observation of child's practice, and to assess progress or evolution in the three components (structural, functional and technical) forming the model. The summation of these three components is called "guiding principle" which organize five conative stages, from novice (1) to expert (5) (Bui-Xûan, 1999). Subjects identify their stage and observe their progress in the practice of sport. Progress of the intervention program is 
associated with a teaching activity adapted to the stage that best encourages acquiring of new skills and progressing from one stage to the next. Subjects were evaluated individually and the activity program was adapted for each subject at the stage that met the subject's ability.

The aims and objectives were explained carefully to each subject. Written, informed consent was obtained from the children and their parents. The study was approved by the local ethics committee, and all procedures were performed in accordance with the ethical standards of the Helsinki Declaration of 1975 as revised in 2008 and the European Good Clinical Practices and the European Good Clinical Practices and with the ethical standards of the sport and exercise science research (Béghin, Castera, Manios, Gilbert, Kersting, De Henauw, et al., 2008; Harris \& Atkinson, 2011).

\section{Measurements}

Measurements included age, height, weight, body mass index (BMI), body composition and ability to perform sport activities. Data were collected at baseline and at the end of one year.

\section{Patients characteristics}

Body mass was measured without shoes and heavy outer garments to the nearest $0.1 \mathrm{~kg}$ using an electronic scale (Oregon Scientific ${ }^{\circledR}$, GA 101, USA). Height was measured without shoes to the nearest $0.1 \mathrm{~cm}$ using a standard physician's scale. Body Mass Index (BMI) was calculated by weight $(\mathrm{kg}) /$ height $\left(\mathrm{m}^{2}\right)$, and was converted to Z-score of BMI.

Total fat and fat free mass were assessed using bioelectrical impedance analysis (AKERN®, BIA101 AKERN, Italy). Following a 5 minute rest subjects were placed in a supine position with arms and legs in abduction between 30 and $40^{\circ}$ from the trunk. Electrode tape, conductivity gel, and current electrodes were placed on the dorsal surfaces of the right hand 
and foot at the distal metacarpals and metatarsals, respectively (Houtkooper, Going, Lohman, Roche, \& Van Loan, 1992). Detector electrodes were applied at the right pisiform prominence of the wrist and between the medial and lateral malleoli at the ankle (Kushner \& Schoeller, 1986). Subjects were instructed to avoid eating for two hours prior to testing. Shoes, socks, watches and jewelry were removed. Subjects were non hydrated and were requested to void the bladder prior to testing. Bio electrical impedance gives a value, expressed in resistance (R). This value is incremented in the equation of Houtkooper et al. to calculate fat mass, fatfree mass for all participants (Houtkooper, et al., 1992).

\section{Ability to perform sport activities (conative curriculum)}

Conative curriculum is organized into five stages, from novice (1) to expert (5) in order to assess and observe the progress in the performance of sport (Vanhelst, Béghin, Fardy, BuiXuan, \& Mikulovic, 2012). Ability to perform sport activities was assessed using scales developed for team sports, e.g. soccer, handball, basketball, and net sports, e.g. tennis, badminton, volleyball. The five levels in conative curriculum are described elsewhere (Vanhelst, et al., 2012).

\section{Statistical analysis}

Data were analyzed using the Statistical Package for the Social Sciences, Windows 11.5 (SPSS Inc., Chicago, IL, USA), Excel 2003 (Microsoft Inc., Redmond, WA, USA) and Sphinx (Chavanod, France). Means were calculated at baseline and following intervention and were compared by paired $t$ tests to assess the effects of the intervention program. Measures included Z-score of BMI, the age and the stage of conative curriculum. The chi square test was used to assess the interactions between these three variables during the 
intervention program. A $p$ values $<0.05$ were taken to be significant with a $95 \%$ confidence interval.

\section{Results}

Subjects are described in Table 1. Significant improvements are observed between pre and post intervention for the $\mathrm{Z}$ score of BMI (Table 2). No significant difference was observed for change of body composition, i.e. fat and fat free mass. The conative curriculum of subjects increased significantly $(\mathrm{p}<0.05)$. Thirty-five of thirty-seven subjects improved significantly in team sport $(\mathrm{p}<0.0001)$ (Table 3$)$. Compared to team sports, fewer subjects improved in net sports although gains were significant $(\mathrm{p}<0.05)(24 / 37)($ Table 3$)$.

The mean ages where $\mathrm{Z}$ score of BMI decreased, stagnated, or increased was 12.3, 15.6 and 13.9, respectively. The effectiveness of the program on anthropometric measures was greater on children than adolescents. Best results were observed in subjects equal to or less than 12 years. $100 \%$ of obese youth aged less than 12 years improved $\mathrm{Z}$ score of BMI whereas $20 \%$ of subjects more than 12 years of age improved their $\mathrm{Z}$ score of BMI $\left(\chi_{2}=2.77\right.$, $\mathrm{df}=1, p<$ 0.05). $95 \%$ of obese youth 12 years of age or less improved the ability to perform team sports while $57.9 \%$ of subjects improved skills in net sports $\left(\chi^{2}=2.81, \mathrm{df}=1, p<0.05\right) .100 \%$ of obese youth aged more than 12 years of age improved the ability in net and team sports.

\section{Discussion}

Adolescence is a crucial period of life where lifestyle habits are established and persist until adulthood. The purpose of this study was to assess the influence of age and type of physical activity in obese youth participating in a rehabilitation program. Results suggest that there is a difference in the effectiveness of the program according to age and type of physical activity training. The program had more effect on improving team sports vs net sports and 
improvements in $\mathrm{Z}$ score of BMI were greatest for those subjects equal to or greater than 12 years.

Results from the present study showed that intervention was more beneficial for children 12 years of age or less vs children more than 12 years old. The age associated with greatest change corresponds to puberty (Cheng, Buyken, Shi, Karaolis-Danckert, Kroke, Wudy, et al., 2012). The effect of the pubertal development on physical changes, e.g. substrate oxidation, insulin resistance, vitamins, blood serum, BMI, adiposity has been well studied and should be taken into account in studies of overweight or obese youth (Brandou, Savy-Pacaux, Marie, Brun, \& Mercier, 2006; Khadgawat, Thomas, Gahlot, Tandon, Tangpricha, Khandelwal D, et al., 2012; Lewitt, Baker, Mooney, Hall, \& Thomas, 2012 ; Molnar \& Schutz, 1998). These studies concluded that pubertal status should be taken into account in studies of overweight or obese youth. Brandou et al showed that the influence of age on the ability to oxidize fat at exercise is explained by the pubertal increase in fat fee mass. Authors demonstrated in markedly obese children during puberty, the ability of fat free mass to oxidize fat at exercise decreases (Brandou, et al., 2006). This conclusion may explain the difference between the two age categories. Even if obese youth increased fat free mass at the end of the intervention program, the improvement was not sufficient to overcome the effect of decreasing of fat oxidation by the fat free mass. Our results are in accordance with the studies showing the difficulty after puberty, to use fat oxidation to enhance lipolysis and diminish adipose tissue and the consequences of obesity (Molnar \& Schutz, 1998; McMurray \& Hosick, 2011; Brandou, et al., 2006; Maffeis, Pinelli, \& Schutz, 1995). However, we cannot completely confirm these conclusions because the program does not include data on the subjects' puberty stage. Other factors, such as daily physical activity, may also explain the improvement of anthropometric measures in children and not in adolescents. Knuth \& Hallal (2009) showed that physical activity in youth decreased with increasing age, including a lower level of 
activity in physical education classes. In this program, whether children or adolescents, the time spent in moderate to vigorous physical activity during one week is not different (data not shown).

Another outcome of the present study was the necessity to differentiate the physical activity training according to the type of exercise. Adolescents improved their skills in team and net sports whereas children improved more in team v. net sports. No explanation on this topic is referenced in the literature. Perhaps there is less improvement in net sports because these activities, e.g. tennis, badminton, and table tennis have more complex movements than team sports. Results from our study on this topic are important in designing intervention programs for obese youth. Indeed, the intervention program has to be enjoyable in order to maintain interest and motivate subjects to adhere. The participant must never be in a failure situation which might lead to decreased activity. The child is positioned in a positive evolutionary dynamics in order to increase self-esteem that will lead a better management of overweight. Therefore, intervention strategies have to be different according to the age of the patient. Our results show that engaging in team sports has a greater impact on anthropometric measures and on the improvement on their ability for both age categories. Therefore team sports should be preferred for children. Net sports are better for adolescents than children.

The current study is unique in that it represents a 1-year health-wellness intervention program of physical activity for obese youth with a conative educational approach. The use of the conative curriculum permits subjects to be evaluated individually and to adapt the activity program according to the subject's ability. The study is limited because no control group was included. Future research could included a larger wide participants adding a control group.

In summary, results show that the intervention should take into account differences in age when designing intervention strategies for obese youth and adolescents. Team sports as a physical activity training intervention are more favourable than net sports for this age group. 
The findings suggest also that the intervention program in obesity is more favourable for children (pre pubescent) than adolescents (post pubescent).

\section{Acknowledgements}

The authors thank the children and their parents for taking part in the study. There is no funding for this study. The authors declare that they have no competing interests. 


\section{REFERENCES}

Achten J, Gleeson M, Jeukendrup AE. Determination of the exercise intensity that elicits maximal fat oxidation. Med Sci Sports Exerc (2002); 34: $92-7$.

Atlantis E, Barnes EH, Singh MA. Efficacy of exercise for treating overweight in children and adolescents: a systematic review. Int J Obes (2006); 30: 1027-40.

Béghin L, Castera M, Manios Y, Gilbert CC, Kersting M, De Henauw S, Kafatos A, Gottrand F, Molnar D, Sjöström M, Leclercq C, Widhalm K, Mesana MI, Moreno LA, Libersa C. Quality assurance of ethical issues and regulatory aspects relating to good clinical practices in the HELENA Cross-Sectional Study. Int J Obes (2008); 32: S12-18.

Brandou F, Savy-Pacaux AM, Marie J, Brun JF, Mercier J. Comparison of the type of substrate oxidation during exercise between pre and post pubertal markedly obese boys. Int $J$ Sports Med (2006); 27: 407-14.

Bui-Xuan G. Modeling process teaching: Teaching Physical Education. (Ed G. Bui-xuan \& J. Gleyse) (1999) Clermont Ferrand.

Cheng G, Buyken AE, Shi L, Karaolis-Danckert N, Kroke A, Wudy SA, Degen GH, Remer T. Beyond overweight: nutrition as an important lifestyle factor influencing timing of puberty. Nutr Rev (2012); 70: 133-52.

Chin S, Rona JR. Can the increase in body mass index explain the rising trend in asthma in children? Thorax (2001); 56: 845-850. 
Dahlberg L, Bergkvist D, Hekmat K, Svensson T. Strong connection between overweight/obesity and orthopedic complaints. Consequences of the obesity epidemic widen. Lakartidningen (2008); 105: 2246-2248.

Dietz WH. Childhood weight affects adult morbidity and mortality. J Nutr (1998); 128: 411414.

Ekelund U, Griffin SJ, Wareham NJ. Physical activity and metabolic risk in individuals with a family history of type 2 diabetes. Diabetes Care (2007); 30: 337-42.

Epstein LH, Paluch RA, Beecher MD, Roemmich JN. Increasing healthy eating vs. reducing high energy-dense foods to treat pediatric obesity. Obesity (2008); 16: 318-26.

Field AE, Cook NR, Gillman MW. Weight status in childhood as a predictor of becoming overweight or hypertensive in early adulthood. Obes Res (2005); 13: 163-9.

Gozal D, Kheirandish-Gozal L. Obesity and excessive daytime sleepiness in prepubertal children with obstructive sleep apnea. Pediatrics (2009); 123: 13-18.

Harriss DJ, Atkinson G: Update-Ethical standards in sport and exercise science research. Int J Sports Med (2011); 32: 819-821.

Horowitz JF, Klein S. Lipid metabolism during endurance exercise. Am J Clin Nutr (2000); 72: $558 \mathrm{~S}-63 \mathrm{~S}$. 
Houtkooper LB, Going SB, Lohman TG, Roche AF, Van Loan M. Bioelectrical impedance estimation of fat-free body mass in children and youth: a cross-validation study. $J$ Appl Physiol 1992; 72: 366-373.

Jasik CB, Lustig RH. Adolescent obesity and puberty: the 'perfect storm'. Ann N Y Acad Sci (2008); 1135: 265-279.

Khadgawat R, Thomas T, Gahlot M, Tandon N, Tangpricha V, Khandelwal D, Gupta N. The Effect of Puberty on Interaction between Vitamin D Status and Insulin Resistance in Obese Asian-Indian Children. Int J Endocrinol (2012); 2012: 173581.

Knuth AG, Hallal PC. Temporal trends in physical activity: a systematic review. J Phys Acti Health (2009); 6: 548-59.

Kushner RF, Schoeller DA. Estimation of total body water by bioelectrical impedance analysis. Am J Clin Nutr (1986); 44: 417-424.

Lazzer S, Busti C, Agosti F, De Col A, Pozzo R, Sartorio A. Optimizing fat oxidation through exercise in severely obese Caucasian adolescents. Clin Endocrinol (2007); 67: 582-8.

Lewitt MS, Baker JS, Mooney GP, Hall K, Thomas NE. Pubertal stage and measures of adiposity in British schoolchildren. Ann Hum Biol (2012); 29: 440-447

Maffeis C, Pinelli L, Schutz Y. Increased fat oxidation in prepubertal obese children: a metabolic defense against further weight gain? J Pediatr (1995); 126: 15-20. 
Mcmurray RG, Harrell JS, Bangdiwala SI, Bradley CB, Denug S, Levine A. A school-based intervention can reduce body fat and blood pressure in young adolescents. J Adolesc Health (2002); 31:125-132.

McMurray RG, Hosick PA. The interaction of obesity and puberty on substrate utilization during exercise: a gender comparison. Pediatr Exerc Sci (2011); 23: 411-31.

Mikulovic J, Bui-Xuân G, Marcellini A. Social and professional reintegration of the longterm unemployed disabled. Intervention on the body through adapted physical activities, conative teaching skills and social re-energization. Int J Rehabil Res (2002); 25: 47-50.

Molnár D, Schutz Y. Fat oxidation in nonobese and obese adolescents: effect of body composition and pubertal development. J Pediatr (1998); 132: 98-104.

Pedersen BK, Saltin B. Evidence for prescribing exercise as therapy in chronic disease. Scand JMed Sci Sports (2006); 16: S3-S63.

van Dale D, Saris WH, ten Hoor F. Weight maintenance and resting metabolic rate 18-40 months after a diet/exercise treatment. Int J Obes (1990); 14: 347-59.

Vanhelst J, Béghin L, Fardy PS, Bui-Xuan G, Mikulovic J. A conative educational model for an intervention program in obese youth. BMC Public Health (2012); 12: 416.

Vanhelst J, Marchand F, Fardy P, Zunquin G, Loeuille GA, Renaut H, Mikulovic J, Hurdiel R, Béghin L, Theunynck D. The CEMHaVi program: control, evaluation, and modification of lifestyles in obese youth. J Cardiopulm Rehabil Prev (2010); 30:181-5.

Von Mutius E, Schwartz J, Neas LM, Dockery D, Weiss ST. Relation of body mass index to asthma and atopy in children: the National Health and Nutrition Examination Study III. Thorax (2001); 56: 835-838. 
Wabitsch M, Hauner H, Heinze E, Muche R, Bockmann A, Parthon W. Body-fat distribution and changes in the atherogenic risk-factor profile in obese adolescent girls during weight reduction. Am J Clin Nutr (1994); 60: 54-60.

Whitaker RC, Wright JA, Pepe MS, Seidel KD, Dietz WH. Predicting obesity in young adulthood from childhood and parental obesity. N Engl J Med (1997); 337: 869-73. 
Legends

Table 1. Physical characteristics of subjects $(\mathrm{n}=37)$

Table 2. Pre and Post intervention mean differences in $\mathrm{Z}$ score of BMI and the stage obtained

in conative curriculum $(\mathrm{n}=37)$

Table 3. Evolution of participants after the intervention program $(n=37)$ 
Table 1. Physical characteristics of subjects $(n=37)$

\begin{tabular}{lcc}
\hline & Boys & Girls \\
\hline Number & 18 & 19 \\
Age $(\boldsymbol{y} r)$ & $12.2 \pm 2.8$ & $12.7 \pm 3.1$ \\
Weight $(\mathbf{K g})$ & $79.5 \pm 25.3$ & $78.3 \pm 26.8$ \\
Height $(\mathbf{c m})$ & $156.9 \pm 15.9$ & $155.3 \pm 14.6$ \\
BMI $\left(\mathbf{K g} / \mathbf{m}^{\mathbf{2}}\right)$ & $31.3 \pm 6.1$ & $31.1 \pm 6.1$ \\
\hline
\end{tabular}


Table 2. Pre and Post intervention mean differences in $\mathrm{Z}$ score of BMI and the stage obtained in conative curriculum $(\mathrm{n}=37)$

\begin{tabular}{|c|c|c|c|c|c|}
\hline & & Pre intervention & Post intervention & $\Delta$ & $\Delta(\%)$ \\
\hline $\mathrm{Z}$ score of BMI & & $5 \pm 1.9$ & $4.5 \pm 1.9^{*}$ & -0.4 & -8.7 \\
\hline Fat mass $(\mathrm{kg})$ & & $39.1 \pm 6.6$ & $37.4 \pm 6.4$ & -1.7 & -4.3 \\
\hline Fat Free Mass $(k g)$ & & $60.9 \pm 6.6$ & $62.6 \pm 6.4$ & +1.7 & +2.8 \\
\hline \multicolumn{6}{|l|}{ Conative Curriculum } \\
\hline & Team sport & $1.3 \pm 0.5$ & $3 \pm 0.5^{*}$ & +1.7 & +90 \\
\hline & Net sport & $1.3 \pm 0.6$ & $3 \pm 0.7^{*}$ & +1.7 & +52.9 \\
\hline
\end{tabular}


Table 3. Evolution of participants after the intervention program $(n=37)$

\begin{tabular}{lccc}
\hline & Decrease & Stagnation & Improvement \\
\hline Team sport $(\mathrm{n}=37)$ & 0 & 2 & $35^{*}$ \\
Net sport $(\mathrm{n}=37)$ & 0 & 13 & $24^{\dagger}$ \\
\hline$* \mathrm{p}<0.0001$ & & & \\
${ }^{\dagger} \mathrm{p}<0.05$ & & &
\end{tabular}

